\title{
Os fundamentos teóricos para a criação da SUDENE: uma análise do pensamento de Celso Furtado e seu conceito de
}

História

\author{
The theoretical foundations for the creation of SUDENE: an analysis of Celso Furtado's \\ thought and his concept of History
}

\author{
Neilane Ramos Rocha de Lima \\ Doutora em História \\ Professora do Departamento de História da Universidade Estadual de Maringá \\ neilane007@yahoo.com.br
}

\begin{abstract}
Resumo: As instituições são frutos das ideias e dos conceitos, assim observar o ideário existente na criação e essência da SUDENE é dar voz ao seu criador, um dos principais economistas do século XX no Brasil Celso Furtado. Portanto, temos como objetivo central desse trabalho a análise de um dos conceitos fundamentais no pensamento de Furtado, o conceito da dinâmica da História, que estaria ligado a ideia de o que o subdesenvolvimento existente no Nordeste é consequência de um processo histórico. Este contexto se constitui de problemas econômicos de ordem estrutural, que precisam e podem ser corrigidos pela ação racionalizada do Estado, para tanto, a contribuição de Furtado para a criação da SUDENE expressa sua teoria em ação. Para tal tarefa, foram selecionadas como fontes as obras mais importantes do economista, no contexto que antecede a criação da SUDENE, entre os anos de 1954 à 1959, momento crucial para a reflexão acerca do conceito de passado e sua relação didática com o presente. Essa perspectiva se tornou uma ferramenta metodológica importante para a elaboração teórica de Furtado. Elementos da história das ideias, história dos conceitos e história dos intelectuais foram utilizados, na medida em que tratamos o intelectual em um lugar histórico, que influenciou suas ideias e conceitos. O método de análise das fontes e de sua autobiografia concomitantemente oferece a percepção dos fatos que não aparecem na teoria, mas que contribuíram para que a mesma exista.
\end{abstract}

Palavras Chaves: Celso Furtado; História; SUDENE.

\begin{abstract}
The institutions are the fruit of ideas and concepts, so to observe the existing ideas in the creation and essence of SUDENE is to give voice to its creator, one of the main economists of the 20th century in Brazil, Celso Furtado. Thus, we have as central objective of this work the analysis of one of the central concepts in Furtado's thought, the concept of the dynamics of History, which it would be linked to the idea that the underdevelopment existent in the Northeast is the consequence of a historical process. This context is constituted of economic problems of structural order, which they need and can be corrected by the rationalized action of the State; therefore, Furtado's contribution to the creation of SUDENE expresses his theory in action. For this task, the most important works of the economist were selected as sources, in the context that precedes the creation of SUDENE, between the years from 1954 to 1959, a crucial moment for reflection on the concept of the past and its didactic relation with the present. This perspective has become an important methodological tool for the theoretical elaboration of Furtado throughout his intellectual trajectory. Elements of the history of ideas, history of concepts and history of intellectuals were used, insofar as we treat the intellectual in a historical place, which influenced his ideas. The method of analyzing the sources and their autobiography concomitantly offers the perception of the facts that do not appear in the theory, but that contributed to its existence.
\end{abstract}

Keywords: Celso Furtado; History; SUDENE. 
A Superintendência de desenvolvimento do nordeste (SUDENE) foi criada em 1959, a partir da articulação de diferentes setores sociais, que partilhavam da preocupação com os altos níveis de pobreza existentes na região do Nordeste brasileiro, principalmente em momentos de graves secas. Nesse processo a figura de Celso Furtado foi de suma importância, pois o mesmo se tornou idealizador da SUDENE. Seu surgimento está intimamente ligado a teoria do desenvolvimento de Celso Furtado, e essa teoria tem como base o conceito de dinâmica da história do economista, ao pensar o subdesenvolvimento brasileiro e suas raízes históricas. Portanto, o seguinte trabalho tem como objetivo central: observar o conceito de história de Furtado existente em sua teoria, que motivou e norteou o ideário de concepção da SUDENE. Para tal fím, abordaremos alguns pontos, sendo eles: a trajetória de vida do economista; elementos centrais de sua teoria do subdesenvolvimento; o ideário e conceito de História de Furtado na criação da SUDENE.

Observar a trajetória pessoal de Furtado é importante para compreendermos suas ideias. Nosso objeto se constitui de ideias e conceitos, analisar o ideário por traz da criação da SUDENE, mas observar esses elementos ao passo que são formulados por um homem, intelectual; não concebemos as ideias fora de um lugar contextual e de uma construção individual.

Mais do que proferir um discurso político ou propagar uma teoria econômica, Celso Furtado buscava entender a razão da história, sua mola propulsora, procurava respostas para o atraso e a estagnação econômica do Brasil, tendo em vista as nações desenvolvidas. E a partir de sua crença, da necessidade da ação do intelectual, não apenas no mundo das ideias, mas também no mundo prático, a SUDENE surge como fruto da ação de um intelectual que se move a partir das ideias para a elaboração de soluções práticas para a superação do atraso brasileiro.

A acepção de intelectual não é unívoca, é polissêmica. Duas dessas acepções são muito utilizadas, conforme Sirinelli (2003: 242): "Estas podem desembocar em duas acepções do intelectual, uma ampla e sociocultural, englobando os criadores e os 'mediadores' culturais, a outra mais estreita, baseada na noção de engajamento [...]'. Furtado se coloca no cenário brasileiro, como um criador de soluções e teorias, de um plano para o desenvolvimento nacional, e se engaja nessa teoria a partir da participação 
ativa na elaboração de planos e órgãos que contribuiriam para que suas ideias fossem colocadas em prática.

Cabe ressaltar, a possibilidade de uso de elementos das três áreas do campo da História, sendo elas: a história das ideias, história dos intelectuais e a história dos conceitos, serão essenciais para pensarmos nossa problemática em diferentes momentos. A história das ideias nos ajuda a pensar o ideário de Furtado, sua construção ao longo de uma linha teórica; a história dos intelectuais nos fornece ferramentas metodológicas a medida que nos leva a pensar o contexto de vida de Furtado e como o mesmo se colocava ao longo de sua produção teórica; por sua vez os postulados de Koselleck , historiador da história dos conceitos, nos ajuda na tarefa de observação do conceito de história e sua relação com o tempo. Portanto, e entrelaçamento das dimensões distintas se faz necessário, pois as necessidades de nosso objeto se colocam no centro da pesquisa.

Esse caso, nos levou a compreender ainda mais a necessidade de rompermos as fronteiras do campo da História, a fim de investigarmos com maior clareza fenômenos históricos que exigem uma visão mais dinâmica e global, captando as melhores ferramentas teóricas e metodológicas, tendo como centro o objeto de pesquisa e as exigências de uma sociedade cada vez mais líquida. Assim, a pesquisa histórica se formata ao passo das nossas próprias transformações, onde romper com fronteiras, ou até mesmo redimensionálas, ampliará nosso horizonte. (LIMA, 2020: 17)

\section{Celso Furtado vida e obra}

Nascido em Pombal, no sertão da Paraíba, em 26 de julho de 1920, no berço de uma família de proprietários de terra e magistrados, Celso Furtado ingressou nos estudos ainda na Paraíba em 1932. Fez os estudos secundários no Liceu Paraibano e no Ginásio Pernambucano em Recife. Ao relatar sobre sua infância relembrou que a grande biblioteca do pai, o ajudou a ter contato com diferentes leituras e também com seu primeiro amor intelectual a História. Em 1939, mudou-se para o Rio de Janeiro, onde, um ano depois, ingressou na Faculdade Nacional de Direito e iniciou seu trabalho de jornalista na Revista da Semana. 
Aos 25 anos, teve o seu livro de contos publicado, mas foi em seu trabalho no serviço público, no Departamento Administrativo do Serviço Público (DASP), em 1943, que observou um despertar para as questões sociais.

Em 1944, concluiu a Faculdade de Direito e entrou para a Força Expedicionária Brasileira (FEB), que o enviou como aspirante oficial para servir junto ao exército americano que estava na Itália. No mesmo ano, por conta de um ferimento, retornou ao Brasil. Em 1948, finalizou seu doutorado em Economia pela Universidade de Paris Sorbonne e produziu sua tese acerca da História Colonial do Brasil. Esta tese deu origem a um de seus principais trabalhos, Formação econômica do Brasil, que o consagrou como um dos maiores intelectuais brasileiros. No mesmo ano, Furtado retornou ao Brasil e voltou a trabalhar no DASP em Niterói. Mais tarde, ainda em 1948, juntou-se ao quadro de economistas da Fundação Getúlio Vargas e trabalhou na revista Conjuntura Econômica. Em 1949, ingressou no grupo de economistas da recém-criada Comissão Econômica para a América Latina (CEPAL), cuja sede era em Santiago. A criação desse órgão foi uma iniciativa das Nações Unidas e tinha como seu primeiro objetivo levantar dados e estudos acerca da economia dos países latino-americanos (FURTADO, 1997).

Portador e norteador da versão da teoria nacional desenvolvimentista ${ }^{1}$, o economista relata a ativa participação na elaboração de projetos para os fins da modernização no governo JK. Em virtude de sua ligação intelectual com a CEPAL, desde 1949, órgão que representava o pensamento desenvolvimentista na América Latina, Furtado difundiu as ideias desse órgão no Brasil e participou da criação de um grupo de estudos específicos sobre Brasil, o Instituto Superior de Estudos Brasileiros (ISEB).

Em 1951, ele visitou universidades dos Estados Unidos em busca de informações sobre o debate - que marcaria a década de 1950 e, nesse momento, estava começando- acerca dos aspectos teóricos do desenvolvimento. Nesse período, intensificaram-se as publicações de Furtado em vários periódicos de circulação nacional e internacional. Também publicou obras importantes, como A economia brasileira (1954); Uma economia dependente (1956); Perspectivas da economia brasileira (1958),

\footnotetext{
${ }^{1} \mathrm{O}$ desenvolvimentismo ou nacional desenvolvimentismo foi um fenômeno histórico observado na ação de determinados governos na América Latina e Brasil, bem como também uma linha de pensamento econômico que se cristalizou no Brasil principalmente a partir da década de 1940. Para mais informações sobre o tema apontamos a obra clássica de Ricardo Bielschowsky $O$ pensamento econômico brasileiro: $o$ ciclo ideológico do desenvolvimentismo. (1995).
} 
fruto de uma série de palestras proferidas em 1957, além de sua obra mais conhecida e citada, Formação econômica do Brasil (1959 a).

Voltou ao Brasil em 1958, desligando-se da CEPAL e assumindo uma diretoria do Banco Nacional do Desenvolvimento (BNDE). Nesse novo momento, suas ideias se cristalizavam com sua participação no governo. O então presidente da república, Juscelino Kubitschek, o nomeou para participar do Grupo de Estudos do Desenvolvimento do Nordeste (GTDN) e, em 1960, da Superintendência de Desenvolvimento do Nordeste (SUDENE). Também teve uma participação importante na formulação do Plano de Metas, plano central do governo de Kubitschek. No governo do presidente João Goulart, em 1962, assumiu o Ministério do Planejamento, elaborando o Plano Trienal.

Após 31 de março de 1964, por meio do Ato Institucional $\mathrm{n}^{\circ}$.1, foi cassado em seus direitos políticos, mudando-se para o Chile, a convite do Instituto LatinoAmericano para Estudos de Desenvolvimento (ILPES). Depois de um tempo no Chile, morou em vários países, dentre os quais Estados Unidos e França, retornando ao Brasil em 1979. Fez viagens em missão de agências das Nações Unidas para África, Ásia e América Latina; lecionou em Cambridge, Inglaterra, e também em Nova York.

Em 1986, foi nomeado Ministro da Cultura, no governo de José Sarney. Sua participação ativa e produtiva nos anos seguintes o fez participar de comissões de estudos, ganhar prêmios e obter um grande reconhecimento intelectual; em 1997, foi eleito para um lugar na Academia Brasileira de Letras. Em 20 de novembro de 2004, faleceu no Rio de Janeiro, deixando para a história uma série de obras que servem até hoje para estudos que se concentram no entendimento da História do Brasil. Isso, não só por estudar a História, mas por fazer parte de uma geração de intelectuais que fizeram de suas ideias ferramentas de um debate, mais que teórico, político. Buscou incessantemente entender os problemas do Nordeste, os quais estiveram presentes em sua infância, de modo a se propor a decifrar os enigmas da história do Brasil e as razões do subdesenvolvimento nacional (FURTADO, 1997). 


\section{O subdesenvolvimento no Nordeste}

Os problemas econômicos do Nordeste ligados a questões climáticas são característicos e antigos da região, no ano de 1879 o Nordeste brasileiro viveu uma de suas maiores secas documentadas ao longo da história do Brasil. Esse momento, ainda sob poder de Dom Pedro II que inicia uma busca por soluções acerca dos problemas econômicos da região do Nordeste brasileiro. A questão hídrica seria o centro dessa discussão, pois as secas já eram realidade. (SOUZA; LIMA; DAVID, 2008).

Ao longo do século XX se observou algumas ações governamentais no sentido de responder ao problema das secas no Nordeste. Em 1909 foi criada a Inspetoria Federal de Obras contra a Seca (IFOCS). Em 1945 esse órgão foi transformado no Departamento Nacional de Obras contra a Seca (DNOCS). No geral esses órgãos estabeleceram ações como construção de açudes e barreiras, na busca por amenizar os efeitos das secas, porém essas ações não tinham eficácia necessária devido a problemas como a má distribuição agrária e de renda, uma vez que muitas dessas obras beneficiavam apenas elites agrárias. Em 1952, após a seca de 1951, foi criado o Banco do Nordeste do Brasil (BNB) com o intuito de financiar, por meio de empréstimos, o aquecimento econômico da região. (SOUZA; LIMA; DAVID, 2008).

Em 1958 o Nordeste viveu um momento de intensas secas, somadas ao contexto de altos níveis de inflação que assolavam a economia brasileira naquele ano, o que agravou a situação econômica do Nordeste. Segundo Furtado (1997), as eleições para governadores estaduais e para o Congresso em 1958 demonstraram o descontentamento da população, pois, com a vitória da oposição nos estados da Bahia e de Pernambuco, o Nordeste se mostrava como um fator desestabilizador do contexto político nacional; esse cenário se soma à emergência de movimentos sociais, advindos de associações camponesas que reivindicavam direitos. Para Furtado, Juscelino Kubitschek (JK) via essa situação com "nervosismo", porém seria necessário tirar o foco da construção de Brasília, sua meta primordial, e pensar os graves problemas políticos e econômicos que o Nordeste representava. "[...] O Nordeste seria o maior 'problema nacional', e a construção de Brasília em nada contribuía para minorá-lo. $\mathrm{O}$ 'abandono' da região estaria gestando tensões que terminariam por ameaçar a unidade nacional [...]”. (FURTADO,1997: 66). 
Recém-chegado da Europa, Furtado renunciou a um cargo nas Nações Unidas para aceitar o cargo de diretor no BNDE (Banco Nacional de Desenvolvimento), e, como condição, o economista assumiria atuação na área das questões do Nordeste. Ao assumir o cargo, Furtado relatou em sua autobiografia que interveio diretamente no Grupo de Trabalho para o Desenvolvimento do Nordeste (GTDN), um dos grupos instituídos pelo BNDE. O GTDN se tornou então um órgão de assessoria direta à presidência da República nos assuntos relacionados ao Nordeste.

Uma questão apontada por Furtado (1997) é que no GTDN não havia economistas especializados em desenvolvimento, e as informações que o grupo tinha acerca da realidade nordestina eram insuficientes, por essa razão até o momento em que Furtado assume a direção do grupo, não havia resultado de trabalho.

Furtado prestou um trabalho importante para o conhecimento econômico do Brasil, ao organizar informações sobre a economia da América Latina e do Brasil, quando estava na CEPAL, especificamente nesse momento os dados da economia do Nordeste também foram levantados. A base para suas observações sobre a questão econômica do Nordeste era fundamentada com dados, estatísticas, números conhecimento dos problemas estruturais da região, que foram utilizados em várias análises existentes no relatório do GTDN.

Portanto, as soluções dadas pelo GTDN, a proposta da elaboração da SUDENE e suas atribuições, são resultados de um olhar aos dados, números da realidade do país, bem como as questões históricas da formação do Brasil.

Assim, com a crença na responsabilidade das instituições governamentais, munidas de conhecimento técnico, na missão de promover um ambiente propício para o desenvolvimento. Furtado se portou como um intelectual de ação, que se apoiava na crença da necessidade de reformas, e não ações isoladas de determinados governos passageiros.

Sendo assim, integrando o GTDN Furtado (1997) elabora um documento intitulado Uma política de desenvolvimento econômico para o Nordeste, o qual afirma ter sido escrito rapidamente, sem ter tido tempo de revisão de outros membros do então grupo. Apesar de o relatório ser de sua autoria, o economista preferiu não colocar seu nome, mas dar ao grupo a autoria, o que para ele posteriormente foi interessante, pois, por motivo de perseguição política que sofreu após 1964, se esse documento estivesse com seu nome provavelmente não seria utilizado como foi para reflexões acerca da questão do Nordeste. 
Frente ao relato, também houve a sugestão de Furtado para o então presidente da república, da necessidade de substituição do Conselho de Desenvolvimento do Nordeste (CODENO) por um órgão mais atuante, o qual tivesse seu foco nas questões estruturais que precisavam de atenção; era uma proposta reformista que se consolidou na SUDENE.

Cabe ressaltar que o projeto da SUDENE sofreu rejeição de parte do congresso, um dos motivos era a própria figura de Furtado que carregava a marca do reformismo, outra questão era a representatividade que os interesses da oligarquia nordestina tinham na Câmara. A resistência política aos projetos que pretendiam reformas estruturais no Nordeste era evidente, em vários momentos citadas por Furtado. Além disso, segundo Lima (2008), o projeto da SUDENE estava sob "fogo cruzado" das demandas municipais e estaduais.

[...] A classe dirigente e a elite política da região nada fariam para modificar o quadro estrutural existente. Sem pressão de fora, as velhas estruturas continuariam a reproduzir-se, até que, um dia, explodisse a caldeira. Fosse o Nordeste um país, sua evolução histórica seria similar à das repúblicas centro-americanas, onde a via para a mudança tem sido frequentemente a violência. Somente porque não era um país cabia pensar em uma 'revolução dirigida', graças a apoios obtidos em outras regiões. (FURTADO, 1997: 111).

Ainda no período que esteve no CODENO, Furtado (1997) foi acusado de "bolchevizar o Nordeste", em suas palavras, tal era a pressão contra as reformas.

Porém, em 27 de maio de 1959, foi aprovada na Câmara dos deputados o projeto de criação da SUDENE, e em 15 de dezembro do mesmo ano foi sancionada a Lei $\mathrm{n}^{\circ}$ 3.692 que concretizou sua existência.

Para Furtado (1997), antes da SUDENE, as ações emergenciais do governo em períodos de secas impedia que muitos morressem de fome, mas por outro lado essa situação impedia o processo de imigração dessa população e reestruturação da economia regional. Também, ao permanecerem, essas pessoas alimentavam as estruturas tradicionais, fortalecendo os curais eleitorais, presas a um contexto de dominação e subsistência. Essas ações emergenciais não contemplavam as raízes do problema no Nordeste, não atacavam as questões estruturais que ao longo dos séculos se reproduziam. A partir da proposta de Furtado que se cristalizou com a SUDENE, o 
plano de ação seria outro, seria focar nos problemas estruturais, historicamente construídos e não diluídos com o tempo, pelo contrário, agravados.

\section{História e Subdesenvolvimento}

Furtado buscou entender a dinâmica da reconstrução no pós-guerra, que ideias regiam os governos em suas tentativas de superação da crise econômica e de avanço social. Sua expectativa era de que elas serviriam de molde para outras nações ocidentais.

As ideias de Mannheim, por cuja admiração ele foi direcionado a viver não só como um pensador, mas como um intelectual que pensava na ação e na transformação do presente, que via e vivia a realidade da reconstrução, seriam importantes para Furtado. Tal transformação, na visão de Furtado, não surgiria do marxismo ou da economia de mercado, mas de uma reconstrução institucional. Dependeria, portanto, do poder burocrático, como previu Max Weber. Ao analisarmos a SUDENE e a participação de Furtado nesse órgão, verificamos o caráter das ideias em prática, do intelectual em ação e militante da transformação.

O mundo em reconstrução econômica abria possibilidades nesse sentido; um exemplo foi o Plano Beveredge, cuja finalidade era diminuir os abalos sociais na Inglaterra no período de crise. Furtado, porém, acreditou que esse tipo de intervenção estatal ainda era pouco. Em sua ótica de economista, seria necessária uma planificação maior e racionalizada e o exemplo mais real dessa prática seria o da URSS. Este despertaria o interesse de Furtado.

A experiência de vida do autor, os lugares por onde passou, as nações que despertaram seu interesse, tudo sempre foi direcionado para a busca de respostas para a realidade do Brasil.

Nos anos em que viveu na Europa em reconstrução, suas ideias se defrontavam com o capitalismo e suas consequências. Para ele, o capitalismo era o sistema que elevaria a riqueza, que criaria bens de consumo para a sociedade, mas os custos de sua manutenção seriam motivadores das grandes guerras. Foi nesse contexto que buscou compreender as raízes da história do Brasil e identificou os problemas estruturais que 
responderiam às perguntas que o perseguiam: quais as causas do atraso econômico brasileiro; qual o caminho para o desenvolvimento?

Cabe salientar que a questão do subdesenvolvimento estava sendo discutida amplamente nos final dos anos 1940 e ao longo dos anos de 1950 e 1960, principalmente em relação aos países da América Latina, que se encontravam a margem no processo de desenvolvimento.

Assim, por meio da Cepal, criou-se o conceito de produtividade social, um mensurador da força produtiva da nação. Com base na disponibilidade técnica, no aperfeiçoamento industrial, que traria maior dinâmica para as economias latinas, a produtividade teria seu crescimento real, favorecendo, assim, não só a superação do atraso, mas também a dependência econômica de outros países. Para isso, seria necessária uma ação planejada e executada pelo Estado.

Um dos aspectos originais da interpretação cepalina de Furtado quanto ao problema do subdesenvolvimento latino está em seu método de análise dos fatores históricos de cada realidade. Com base neles, seria possível definir as deficiências de cada caso; identificadas as debilidades, caberia aos planejadores prever uma forma de potencializar os meios e os recursos já existentes; esse plano seria dirigido diretamente pelo Estado, que transformaria até mesmo estruturas institucionais se preciso fosse.

Uma das mais importantes distinções entre os cepalinos e Furtado_y compris a teoria clássica e a neoclássica_ é que Cepal e Furtado fundem teoria e história; não fosse assim, seria possível encontrar uma teoria de 'centro' e 'periferia' desde Smith, o que não ocorre, e não por acaso: é que suas concepções são inteiramente homogeneizadoras, fazem tábula rasa da história, pois as 'leis' do capital seriam aplicáveis urbi et orbi; daí a teoria de comércio internacional de Ricardo, por exemplo, que vê vantagens comparativas entre países diferentes, quando na verdade o domínio colonial e posteriormente das principais economias desenvolvidas determina de fora para dentro as 'vocações' primárias das colônias e depois ex-colônias (ARAÚJO, 2009: 46).

Para Love (1998), Furtado foi um grande escritor brasileiro estruturalista que aplicou sua teoria de forma original e pioneira na observação do subdesenvolvimento. 
Esse autor considera Furtado como o elo entre a Cepal e os estudos estruturalistas no Brasil.

Furtado sempre foi um intelectual emergido em seu tempo: as questões que o levavam ao passado eram as do seu presente. Ele era um economista inteiramente envolvido nos debates teóricos e não levava a bandeira de nenhum partido; era adepto do capitalismo, mas crítico do livre mercado. Furtado participou de um momento de grande agitação, no qual os intelectuais e a Cepal, por meio de sua figura no Brasil, opunham-se à teoria liberal monetarista. Com o Manifesto da Cepal, texto de Raúl Prebish, documento que inaugurou e sinalizou o pensamento cepalino, Furtado se expôs ao debate com os defensores do livre mercado. (BIELSCHOWSKY, 1995).

$\mathrm{Na}$ teoria de Keynes, que fundamentou o pensamento de um dos mais importantes economistas da Cepal, Raul Prebisch, a proposta era analisar a produção e a demanda efetiva como um caminho para se entender a crise no capitalismo. Focada na realidade presente e excluindo o passado da interpretação, essa era uma visão sincrônica do fenômeno do problema econômico nacional.

Em vez de reduzir a realidade a um modelo, esforcei-me em adotar um enfoque histórico, abarcando o que cabia e o que não cabia no marco explicativo do economista. A visão de Prebisch era essencialmente sincrônica: assinalava uma descontinuidade estrutural no sistema capitalista, geradora de dinâmicas distintas nos segmentos central e periférico [...] (FURTADO, 1997:163).

Existiria assim uma diferença analítica entre Prebisch e Furtado. O primeiro possuía uma visão sincrônica; o segundo observava diacronicamente a questão econômica na América Latina, dando enfoque nos processos históricos.

Em sua interpretação diacrônica, Furtado não concebia outro caminho a não ser a o da observação estrutural do passado para compreender o subdesenvolvimento; este não seria um momento de crise capitalista, mas sim de falta do próprio acúmulo de capital. Assim, o estudo sobre o subdesenvolvimento ocorria com base em uma nova leitura da História.

O autor acreditou ser possível elaborar um método de entendimento da História que correspondesse às suas expectativas acerca da compreensão do processo de desenvolvimento econômico (FURTADO, 1985). Sua teoria não se fundamentava na 
espontaneidade do livre mercado, como acreditavam os liberais, nem tampouco na espontaneidade do aumento da exploração com o desenvolvimento do capitalismo, como postulavam os marxistas. (FURTADO, 1961).

Nesse sentido, a análise da história do Brasil levou Furtado à formulação de esquemas para compreender a estrutura do desenvolvimento econômico ou mesmo do subdesenvolvimento. Baseou-se na macroeconomia, por meio da qual podia visualizar o desenvolvimento do capitalismo e chegou à conclusão de que os preços, a geração e a distribuição de renda podiam ser gerenciados pelo Estado.

$\mathrm{Na}$ ótica do economista, entender o processo histórico implicou na busca por respostas para a reorientação da própria história. Por meio da racionalidade, seria possível modificar, alterar o destino de subdesenvolvimento. A racionalidade seria mais eficiente que a ação do mercado.

Empreender a batalha contra o atraso acumulado e construir um sistema de forças produtivas mais avançado significaria necessariamente buscar uma racionalidade mais abrangente que aquela dada por orientação do mercado, tendo o planejamento como uma técnica social que ordenasse a ação estatal, engendrasse um horizonte temporal mais largo, duradouro e racional. $\mathrm{Na}$ visão perspicaz de Furtado, só o processo de planejamento poderia lograr revelar os interesses postos, ou seja, tornar menos opacas as relações de poder e os projetos políticos em disputa em cada alternativa escolhida ou a escolher (AGUIAR, 2013: 26).

Furtado buscou traçar um caminho mais seguro para o desenvolvimento, o qual, em sua lógica, também alinharia desenvolvimento ao interesse nacional. Nesse sentido, seria essencial promover uma reforma institucional, com caráter estrutural, para que o Estado se fundisse em novas bases sociais, o que lhe permitiria coordenar interesses conflitantes, a fim de distribuir o desenvolvimento para todas as regiões do Brasil, desfazendo assim as forças que tenderiam a criar a concentração de renda.

Dessa forma, o desenvolvimento, tal qual o processo histórico, seria uma espécie de trajetória em aberto, alheia às diferentes escolhas que alteram as chamadas estruturas. O desenvolvimento real seria vislumbrado no acúmulo de forças que romperiam com as estruturas criadoras do atraso, pois, se a desigualdade perdurasse, o Brasil não teria 
futuro, ao menos não seria civilizado, não seria uma nação, mas uma espécie de colônia, hospedeira de investimentos.

Furtado concebeu o subdesenvolvimento como um fenômeno coexistente ao desenvolvimento, fenômeno esse historicamente construído. Via o subdesenvolvimento como uma estrutura rígida, que não desapareceria com o tempo. Sua estrutura era formada por um contexto no qual estavam englobados o uso de capital disponível não suficiente para a absorção da força de trabalho e a heterogeneidade tecnológica entre os setores da economia.

Segundo o economista, ao comparar o nível de desenvolvimento de diferentes países concluiu que um dos fatores que sinalizavam o subdesenvolvimento eram as disparidades e desequilíbrios dos desenvolvimentos regionais, fato que era visível no Brasil.

Assim, a formação da nacionalidade estaria vinculada à necessidade de um desenvolvimento uniforme entre as regiões, eliminando as desigualdades sociais econômicas existentes. O desenvolvimento do capitalismo não seria natural, espontâneo e principalmente uniforme, contribuindo assim para a concentração de riqueza e exclusão de regiões, como o nordeste, do processo de desenvolvimento.

\section{Problemas e soluções para o Nordeste: a SUDENE em perspectiva}

Nós próximos parágrafos vamos pontuar rapidamente os principais inimigos do desenvolvimento na ótica de Furtado, esses fatores historicamente construídos, explicariam a existência do subdesenvolvimento ${ }^{2}$ no Nordeste.

Iremos apontar os problemas mais graves que Furtado observou no caso do Nordeste, que gerava um cenário de pobreza e subdesenvolvimento. A proposta do GTDN buscava responder a esses problemas, entendendo os mesmo como frutos de um longo processo histórico, que poderia ser superado.

\footnotetext{
2 Tendo em vista os limites do presente trabalho analisamos os conceitos de Furtado dentro do período de recorte temporal, como uma ferramenta metodológica de parte dos historiadores das ideias, em busca de contextualizar os conceitos e ideias, porém para mais referências acerca do conceito de subdesenvolvimento em Celso Furtado apontamos suas seguintes obras: Desenvolvimento $e$ Subdesenvolvimento (1961); Subdesenvolvimento e estagnação na América Latina (1966) Teoria e Política do Desenvolvimento Econômico (1983); Raízes do Subdesenvolvimento (2003).
} 
No início do relatório do GTDN (1959) o economista deixa claro que o Nordeste representava um problema para a situação do desenvolvimento econômico nacional, e essa região era a representação de propostas e orientações para que esse problema fosse solucionado a nível nacional.

A comparação se tornou um caminho para que a problemática do Nordeste fosse contemplada. Uma característica metodológica existente em outras análises de Furtado, ao comparar o ritmo de crescimento da economia nordestina em relação ao ritmo de crescimento da economia do Centro-Sul, fica claro no documento a disparidade existente entre as regiões, e como ao longo dos anos essa distância se acentua.

Algumas causas para o atraso econômico do Nordeste foram destacadas no documento, como: disparidade do nível de renda; escassez relativa de terras aráveis; secas; extrema concentração de renda na economia açucareira; predominância do setor de subsistência na pecuária do interior semiárido; escassez de divisas resultante do processo de política de desenvolvimento, por meio dos subsídios aos investimentos industriais, fruto da política de controle das importações, que garantia vantagem à região Centro-Sul, que já gozava de uma indústria mais forte. Esses fatores aumentavam a distância de diferentes realidades econômicas, entre o Nordeste e o Centro-Sul do Brasil.

A ligação econômica entre regiões como o Nordeste e Centro-Sul se dava de forma díspar, sendo o primeiro apenas fornecedor de matéria-prima, limitando seu papel no mercado, sinalizando a divisão do trabalho dentro do Brasil. Sobre essa questão Furtado (1959a: 12) acrescenta:

Esta articulação, que os estudiosos da economia brasileira, na primeira metade do século XX, apreciaram como foram de evolução tendente a integrar o País em uma só economia, trazia o germe dos problemas que hoje estamos enfrentando, pois reproduzia o mesmo esquema de divisão geográfica do trabalho que viciaria todo o desenvolvimento da economia mundial, com suas metrópoles industrializadas e colônias produtoras de matérias-primas.

Furtado não se esquece das peculiaridades do Nordeste, e leva em consideração o efeito que as secas causam a economia do Nordeste. A questão climática do Nordeste é preponderante para sua situação. No momento em questão o Nordeste vivenciava a 
agricultura de subsistência, um dos setores mais atingidos pela seca, o fator climático gerava uma crise econômica maior do que as crises existentes no sistema capitalista. A produção de alimentos, é atingida pelas secas, traçando um cenário que o documento denomina de "colapso da demanda efetiva", atingindo todo o sistema econômico.

A questão das secas ganhou espaço importante no documento do GTDN, sendo essa situação climática um dos aspectos fundamentais para a compreensão dos problemas do atraso econômico do Nordeste.

Uma das grandes consequências negativas das secas é a intensidade que elas afetam a agricultura de subsistência, gerando crises na economia da região, o que o documento denominou de "calamidade social". A seca atinge grande parte do setor produtivo do Nordeste, aumentando o desemprego e a pobreza. (GTDN, 1959)

Furtado aponta que a crise no setor produtivo aumenta a escassez de alimentos, aumentando o preço desses produtos no mercado, salientando a fraqueza econômica do Nordeste. Assim, a baixa oferta de alimentos se mostrava o problema fundamental do Nordeste, esse fato estaria ligado à falta de terras cultiváveis.

Na faixa litorânea do Nordeste, a agricultura deveria ter a utilização dos recursos de terras e águas potencializada por um melhor uso desses elementos. A região semiárida do Nordeste, mais afetada pelas secas, aumentaria sua dependência do suprimento de alimentos decorrentes de outras regiões, o relatório do GTDN (1959) chamou esse movimento de uma "abertura de nova fronteira agrícola".

Uma questão apontada no relatório é a importância do setor exportador de produtos, tais como: açúcar, algodão, cacau, fumo, couros e peles, oleaginosas e minérios. Esse setor teria garantido o pouco desenvolvimento existente no Nordeste. Porém, até 1953, a política cambial não favoreceu a exportação externa, não dando espaço para o crescimento e desenvolvimento desse setor.

$\mathrm{O}$ setor exportador e o industrial formavam as forças impulsionadoras do desenvolvimento brasileiro, mas, segundo Furtado, os desequilíbrios tornavam a economia frágil. Essa era a situação típica do estágio, da etapa ${ }^{3}$ de desenvolvimento em que o Brasil se encontrava. Para que a indústria se fortalecesse, seria necessária uma

\footnotetext{
${ }^{3}$ É importante ressaltarmos que o conceito de etapa para Furtado seria a ideia de um momento, sua interpretação do subdesenvolvimento não é "etapista", a prova disso seria a persistência de sua existência na região do Nordeste. A visão de Furtado é oposta a tese de Rostow (1974) que em sua obra Etapas do desenvolvimento econômico: um manifesto não comunista observa que o desenvolvimento historicamente se constrói por etapas.
} 
"ação orientadora de seus investimentos e corretora da estrutura de sua procura", como ficou claro na obra Formação Econômica Brasileira.

O crescimento de uma economia depende principalmente da expansão de sua capacidade produtiva e da eficiência com que se utiliza essa capacidade. A expansão da capacidade produtiva consiste, basicamente, em retirar uma parcela da renda corrente e transformá-la em capital reprodutível. Tem se aí a medida do esforço que realiza a economia para crescer. A eficiência na utilização da capacidade produtiva é problema complexo, pois depende de uma série de fatores. (FURTADO, 1959a:15).

A industrialização geraria empregos, criaria uma classe dirigente emergente e nova e auxiliaria a fazer com que o capital resultante do processo econômico de outras atividades ficassem no Nordeste.

Sendo assim, uma das soluções apontadas pelo documento seria a industrialização como elemento central para o desenvolvimento econômico do Nordeste. O que era característico do pensamento da Cepal, bem como do economista era a indústria como elemento central do processo de desenvolvimento econômico. "[...] Sendo assim, o desenvolvimento só é factível mediante a diversificação da própria produção interna, ou seja, pela industrialização [...]" (GTDN, 1959: 10).

Para o processo de desenvolvimento econômico acontecer Furtado (1954) considerava necessário observar que a técnica estava no centro de tudo, o acúmulo de capital era consequência dela e o aumento da produtividade era dependente dela também. No entanto, algumas perguntas permaneciam: como gerar a técnica? Ela é uma condição histórica? E, logo a seguir no texto, respondia: “O desenvolvimento econômico é essencialmente um fenômeno histórico [...]” (FURTADO, 1954: 213).

Segundo Furtado (1954: 195), “O desenvolvimento econômico, conforme dissemos, consiste na introdução de novas combinações de fatores de produção que tendem a aumentar a produtividade do trabalho [...]".

Em sua teoria, Furtado (1954) indica que o desenvolvimento econômico se explica pelo processo de expansão da produtividade do trabalho (técnica). A explicação tem duas formas: primeira, no plano abstrato, pela análise do próprio mecanismo de crescimento; segunda, no plano histórico, pelo estudo crítico em confronto com a realidade das categorias básicas utilizadas na análise abstrata. 
Segundo Oliveira (2003) na obra Formação Econômica Brasileira, Furtado observou que a capacidade produtiva seria elemento chave, para se entender o crescimento econômico, à medida que essa capacidade variava principalmente pela queda das exportações na chamada Grande Depressão. Todavia quando se há a proteção cambial, fazendo com que os preços se elevem, a indústria voltada ao mercado interno ocuparia a capacidade produtiva já existente, aumentando o rendimento do capital, mesmo sem novos investimentos. Assim cada ciclo econômico colocaria uma nova necessidade política, essa questão é resgatada por ele no relatório do GTDN (1959).

Em sua defesa a importância da indústria no Nordeste, ao relatar o contexto de criação da SUDENE, o economista ressalta a capacidade que esse setor teria de desarticular oligarquias, à medida que atrairia novos personagens para o jogo econômico regional, essa solução atacaria um problema estrutural historicamente construído, que acentuava a concentração de renda no Nordeste. “[...] Essa industrialização contribuiria, ademais, para introduzir nas classes dirigentes locais empresários de espírito empreendedor, capazes de neutralizar a influência da oligarquia atual, acostumada a viver de favores e da proteção do governo". (FURTADO, 1997: 79).

A carência de um setor industrial desenvolvido no Nordeste o deixa sempre em níveis inferiores de desenvolvimento em relação ao da região Centro-Sul do Brasil. Até mesmo o capital privado, produzido no Nordeste, se desloca para a região Centro-Sul, deixando o mercado regional desabastecido de investimento e desprovido de novas oportunidades de negócios. (GTDN, 1959)

Outro fator seria de suma importância o desenvolvimento do mercado interno, à medida que o capital produzido no Nordeste não migrasse para outras regiões, mas permanecesse no Nordeste incentivando o aumento da produtividade e sua diversidade, por meio do processo de industrialização.

[...] O desenvolvimento com base no próprio mercado implica progressiva diversificação da estrutura produtiva, exigindo, por isso mesmo, um esforço de industrialização. Cabe, portanto, analisar as causas que vêm dificultando a industrialização do Nordeste, como passo indispensável à formulação de uma política de desenvolvimento. (GTDN, 1959: 49). 
Apesar de a agricultura existir no Nordeste, como em todo o país, ela era limitada pelas questões climáticas da região, e se concentrava principalmente no açúcar, desde o período colonial. “[...] deve-se observar que, sendo uma região escassa de boas terras aráveis, e de elevada densidade demográfica, o Nordeste dificilmente poderá alcançar um nível alto de renda apoiado na exportação de produtos agrícolas [...]" (GTDN, 1959: 51).

O relatório do GTDN a busca nos antecedentes históricos a explicação da falta de fôlego econômico no Nordeste, para que a indústria não se desenvolvesse tal como no Centro-Sul. Dentre algumas questões, podemos destacar a que o documento aponta, do contexto do pós-guerra, em que o Centro-Sul teve sua indústria desenvolvida a partir dos subsídios cambiais e os financiamentos governamentais, realidade essa não vivenciadas pelo Nordeste, a ação do Estado era preponderante nesse processo.

O documento deixa claro que o plano para o fomento da industrialização no Nordeste deveria ter como principais objetivos: “[...] reorganizar as indústrias tradicionais da região, prejudicadas pelos fatores antes referidos, a fim de reconquistar a posição que antes detinham em face do parque industrial do Centro-Sul; segundo, modificar a estrutura do sistema capaz de auto propagação [...]” (GTDN, 1959: 59).

Como resultado dos estudos do GTDN o documento propôs um plano de ação, no sentido de nortear as ações nas diversas frentes de trabalho dos órgãos e grupos de trabalhos instituídos pelo governo federal, incluindo a participação do GTDN, na busca por uma unificação e orientação dessas frentes no processo de execução do planejamento.

As principais tarefas desse movimento de trabalho deveria dar prioridade às seguintes questões: reorganização da situação econômica da região semiárida, principalmente com a abertura de frentes de colonização para tal região; aumento dos investimentos industriais; observação do problema de abastecimento elétrico em determinadas regiões do Nordeste; modernização dos meios produtivos a partir da absorção de tecnologia recentes, como na geração de energia, na proteção dos lençóis d'água; aumento da oferta de alimentos nos centros industriais, principalmente as capitais que sediariam as indústrias; uma das preocupações do GTDN se concentrou na necessidade de ajuda técnica ao governos estaduais, afim de habilitá-los a compreenderem e resolverem os problemas destacados pelo grupo em questão, a partir de medidas governamentais próprias de cada estado; e, por fim, a necessidade da existência de uma articulação geral para a execução do plano. 
O objetivo central do presente Plano de Ação é, partindo de um claro diagnóstico do problema econômico nordestino, tentar modificar o curso dos acontecimentos, pelo ataque simultâneo em um conjunto de frentes consideradas vitais. A primeira meta é tornar o Nordeste mais resistente às secas [...] A segunda meta consiste em elevar a produtividade média da força de trabalho concentrada na faixa úmida [...] intensificação dos investimentos industriais [...]. Em conjunto essas duas metas sintetizam uma política que, se efetivamente executada, poderá modificar a estrutura da economia regional [...]. (GTDN, 1959: 93-94).

É expressiva a teoria de História de Furtado no objetivo central do Plano de Ação desenvolvido pelo GTDN, "tentar modificar o curso dos acontecimentos". A ideia de que o Estado e suas instituições a partir do conhecimento técnico é capaz de alterar e direcionar o fluxo da História. A crença nessa visão de motor da História, estava presente no GTDN, e dava sentido para sua própria existência que se consolidaria na SUDENE.

A participação do Nordeste na elaboração do produto interno bruto do Brasil, estava caindo de forma sistemática, criando um contexto de disparidade social cada vez maior, e essa realidade estava sendo aceita, ao ponto de se institucionalizar, alcançando um estágio de irreversibilidade, a SUDENE seria uma resposta a esse cenário.

[...] A desigualdade econômica, quando alcança certo ponto, se institucionaliza. Tal fato, que observamos nas sociedades humanas_a tendência das desigualdades a se institucionalizarem e a formar classes_, também pode ocorrer entre as regiões do mesmo país [...] E quando um fenômeno econômico dessa ordem obtém sanção institucional, sua reversão espontânea é praticamente impossível. Além disso, com os grupos economicamente mais poderosos são os que detêm o comando da política, a reversão mediante a atuação dos órgãos políticos também se torna extremamente difícil. (FURTADO, 1959b: 15)

Essa situação, que na ótica de Furtado se acentuaria com o passar dos anos, deveria ser tratada como um problema a ser enfrentado de forma focal e emergencial. Sendo assim, necessário, uma "Operação Nordeste". Uma ação coordenada, que não 
pretendia resolver o problema do nordeste a curto prazo, mas que poderia interferir na tendência de empobrecimento que essa região enfrentava e que ameaçaria o grande projeto de consolidação da unidade nacional. "[...] Como um astrônomo que, ao provocar pequena alteração na posição do seu telescópio, desloca a objetiva através de enormes distâncias siderais, acreditamos poder condicionar todo um processo histórico, modificando elementos estratégicos e alterando tendências de setores fundamentais". (FURTADO, 1959b: 16).

A proposta de Furtado seria uma nova maneira de observação do problema econômico do Nordeste, tendo em vista toda a trajetória histórica contemplada anteriormente. Sendo assim a partir de um processo de reforma administrativa, que tinha como um dos cernes uma atuação institucional, a partir da SUDENE, a pobreza no Nordeste poderia ser desnaturalizada, a partir de ações pontuais, pautada nas raízes do subdesenvolvimento regional.

Sobre a importância da SUDENE, Furtado (1959b: 17) mostra: "Não seria possível modificar todo um processo histórico se não partíssemos de uma interpretação desse processo: de uma adequada formulação do problema, ou diagnóstica da situação, como hoje dizemos. Para transformar esse diagnóstico em autêntica política de desenvolvimento, em ação, necessitamos de adequando instrumental administrativo".

A SUDENE surge com o intuito de não ser apenas um setor administrativo tradicional, mas um propagador de uma nova maneira de articular as transformações, a partir de uma nova perspectiva de visão do problema estrutural do Nordeste, uma política de desenvolvimento. Nas palavras do economista a “[...] SUDENE pretende ser um órgão de natureza renovadora como duplo objetivo de dar ao Governo um instrumento que o capacite a formular uma política de desenvolvimento para o Nordeste e, ao mesmo tempo, o habilite a modificar a estrutura administrativa em função dos novos objetivos". (FURTADO, 1959: 18).

Essa nova maneira de observar o nordeste deveria conceber as peculiaridades de cada parte do nordeste, as características de seu clima e solo, para que, a partir de estudos focais, um plano de ação pudesse ser elaborado.

[...] desenvolveu-se na região semiárida, na caatinga, uma economia inadequada ao meio, extremamente vulnerável à seca. O primeiro objetivo deve ser, portanto, criar ali uma economia resistente à seca. Para isso teremos de conhecer melhor a região, seus recursos de água superficial e 
subterrânea, sua flora, e teremos que mobilizar o crédito e a assistência técnica [...] Uma economia de mais alta produtividade, na caatinga, não será compatível com uma grande densidade demográfica. Assim, a reorganização da economia da caatinga criará excedentes populacionais que deverão ser absorvidos alhures. Daí a necessidade de incorporar novas terras ao Nordeste, de deslocar sua fronteira agrícola. (FURTADO, 1959b: 32-33).

Porém, abordando a necessidade que o tempo impôs ao aumento da produtividade, até mesmo à ampliação comercial, ele concluía que a industrialização se tornara uma grande aliada no processo de acumulação de capital. A sociedade que se baseava na economia industrial tinha um desenvolvimento sólido, pois sua economia não era limitada, pelo contrário, foi incrementada e solidificada. Já, em uma economia comercial, principalmente na conjuntura colonial em que não havia possibilidade de desenvolvimento de mercado interno, o desenvolvimento sempre seria superficial, sempre haveria um ponto de saturação e uma dependência de outros mercados.

Para tal dinâmica ser modificada, seria necessário implementar mudanças estruturais para o desenvolvimento da indústria, pois, nessa conjuntura, a técnica e o avanço tecnológico tornariam possível o acúmulo de capital, o lucro circularia em uma esfera dinâmica e sua distribuição poderia ser descentralizada com mais facilidade. $\mathrm{O}$ autor buscou salientar em suas obras que o desenvolvimento histórico das civilizações que tiveram como base a economia comercial era diferente do desenvolvimento das que tiveram como base a indústria, justamente por conta da possibilidade de acumular capital.

\section{A concepção de Furtado acerca da dinâmica da História presente na idealização da SUDENE}

Após o levantamento de importantes informações para a melhor compreensão da questão proposta pelo presente trabalho, iremos ressaltar três pontos que demonstram a concepção da dinâmica da História de Furtado na idealização da SUDENE, sendo eles: análise estrutural dos problemas econômicos do Nordeste, e a crença na transformação e 
correção do passado por ações racionais do Estado e a concepção Moderna de História existente no ideário de Furtado.

Primeiramente, cabe ressaltar que ao mostrarmos os problemas econômicos levantados por Furtado existentes no Brasil, e principalmente no Nordeste, pensamos o processo histórico estrutural que formatou a realidade do subdesenvolvimento. Ao fazer isso elencamos alguns desses problemas. Poderíamos voltar em praticamente todos e encontrarmos suas raízes no passado, mas ressaltaremos aqui três desses problemas que acentuavam a crise econômica na região. Destacamos: a concentração de renda, a falta de dinamismo do mercado interno e a concentração da produção agrícola em poucas culturas, desmotivando o setor industrial.

A região do Nordeste foi um dos temas centrais de Formação Econômica do Brasil, como aponta Araujo (2009), e desde essa obra Furtado se preocupa em apontar que a estrutura construída desde o Brasil Colônia, baseada na monocultura da cana-deaçúcar para exportação resultava em produção de capital que não ficava no Nordeste, ou muitas vezes até mesmo no Brasil, voltava para a metrópole, desmotivando a existência de um mercado interno, concentrando a renda nas mãos de uma oligarquia que ao longo de gerações ainda exercem seu poder político e econômico no Nordeste. “[...] a sociedade formou-se no âmbito das fazendas, onde poder econômico e poder político eram duas faces da mesma moeda e onde os aglomerados urbanos nada mais eram que prolongamentos das fazendas. Esse quadro de isolamento reforçava a situação de dependência do trabalhador rural em face do senhor de terra". (FURTADO, 1989: 22).

Para Furtado esse processo se deu historicamente, criando repetições, elaborando uma estrutura rígida de oligarquias, e esse sistema era reproduzido pelas ações emergenciais de ajuda do Estado ao longo de décadas, como vimos anteriormente. A proposta de incentivar a indústria, para a resolução de muitos problemas já destacados, estaria também na crença de que esse setor levantaria outros personagens econômicos desarticulando as oligarquia. Ou seja, uma problema do passado, seria aos poucos dissolvido, através de ações concretas do Estado na economia do Nordeste. O Estado focando suas forças para destruir sistemas estruturais que sustentavam a existência do subdesenvolvimento. Assim, o Estado a partir do conhecimento técnico, o que Furtado estava provendo para o caso do Nordeste, poderia aplicar políticas direcionadas a promoção do desenvolvimento, reformando antigos órgãos e departamentos em instituições que se concentrariam em problemas mais fundamentais e não emergenciais, como a SUDENE. "[...] Com efeito, o processo econômico, na fase mais avançada do 
capitalismo, exige a atuação progressiva de agentes de decisão centralizadores, como requisito imprescindível à manutenção da estabilidade em condições de desenvolvimento". (FURTADO, 1964: 75).

Essa análise nos leva a pensar o segundo elemento, a ação do Estado como um projeto político, esse projeto político proposto por Furtado previa uma intensificação do intervencionismo estatal na implementação das reformas institucionais necessárias para o ordenamento do capitalismo, planejamento a fim de orientar as medidas mais urgentes, e empregar as reformas necessárias. O fim esperado pelo economista era a consolidação da distribuição de renda para que o subdesenvolvimento pudesse ser combatido de fato.

Sendo assim, a SUDENE era resultado dos estudos e análises técnicas, organizadas em um plano de ação, que atingiria os problemas estruturais, a partir da ação direta do Estado. Ela surge como uma instituição que cristalizava a concepção de dinâmica da História, uma história que tem seus atores no presente, que através da razão traçam seu futuro.

Esse pensamento nos leva a compreensão de que a concepção de Furtado acerca da História era uma visão Moderna, de uma história linear, esse desenvolvimento tão esperado não surgia espontaneamente, como acreditavam os liberais, principalmente por existirem as permanências que resistiam ao longo dos séculos, mas ainda seria uma concepção que acreditava em um futuro de desenvolvimento, em um momento de superação do passado. Onde o passado ensina, sendo assim, pensar o passado e transformar o presente, a fim de elaborar prognósticos de desenvolvimento para o futuro. Esse conceito de motor da História moveu o pensamento e ações de Furtado, ele não se encontra apenas na criação da SUDENE, mas grande parte das realizações intelectuais do economista.

É importante pontuarmos que a concepção de História em Furtado recebe uma influência do próprio desenvolvimentismo, que absorveu o pensamento positivista de Auguste Comte, em que o homem é responsável pela superação do atraso e portanto sua ação consciente move o curso da história. (FONSECA, 2008). "A filosofia comtiana contribuiu para negar a concepção te(le)ológica da história, reforçando a necessidade da atuação humana para a construção de seu próprio destino. Sob o entendimento de que o futuro almejado não adviria espontaneamente, o positivismo suplantou o debate acerca da plausibilidade da intervenção estatal [...]" (FONSECA; SALOMÃO, 2017: 12). 
A noção de "horizonte de expectativa" de Koselleck (2006) ajuda-nos a visualizar como cada intelectual, em seu presente, pensa seu futuro; como, em sua tentativa de prognóstico, ele se pauta na observação do próprio "espaço de experiência", o passado. O passado serviria como uma fonte de informações para responder às questões do presente e forneceria subsídios para a criação de um modelo, um caminho a seguir em busca das soluções para o futuro, ou seja, a superação do atraso econômico.

Furtado é parte de uma geração de intelectuais que acreditava que a história poderia ser fonte de entendimento dos problemas de seu presente, mas não somente isso: o estudo do passado poderia lhe dar indícios para a resolução das causas do atraso, para um projeto de desenvolvimento que, para ele, seria um projeto político. Assim, o teor de seu discurso nos debates era político, pois estes não se eram sobre o passado ou simplesmente sobre o presente: eram principalmente sobre o futuro, ou seja, tinham em vista um projeto de aceleração do tempo no Brasil.

A questão levantada nos escritos de Furtado nos remete ao conceito de processo histórico. Em suas teses, Reinhard Koselleck (2006) observa que toda formação conceitual está intimamente ligada com sua temporalidade. O contexto histórico é que nortearia a formatação das definições que fundamentam os ideários, os projetos políticos, os planos de desenvolvimento, em geral, o pensamento intelectual. Para esse autor, o uso público e político das palavras depende do contexto temporal de elaboração dos conceitos, os quais são norteadores dos discursos.

Furtado, dentre outros, representa uma historiografia voltada para a resolução de um problema do presente. Em razão disso, considerava necessária uma definição conceitual de processo histórico; a partir de tais conceitos, poder-se-iam traçar os planos políticos, as metas governamentais, tendo em vista que a superação da história seria conduzida pela força motriz do Estado. A ideia de "50 anos em 5", postulada pelo governo JK, no contexto de criação da SUDENE, remete-nos à ideia de realidade histórica na qual o Estado se munia de instrumentos para acelerar a história. Um desses instrumentos foi encontrado na justificativa teórica fornecida por intelectuais como Furtado, que acreditavam ser necessária a ação governamental para a superação do subdesenvolvimento. 


\section{Considerações finais}

Foi por intermédio do estudo da história que Furtado observou a diferença entre as condições históricas dos países desenvolvidos e subdesenvolvidos. O que nos prendia ao passado estava estruturado em instituições, compondo um contexto que se propagou no presente, como uma fortaleza. A heterogeneidade econômica do Brasil, a miséria, principalmente do Nordeste, a falta de competitividade e a baixa produtividade eram apenas as pontas dessas estruturas cujas bases estavam no passado.

As condições histórico-estruturais não produziram condições materiais para que os indivíduos pudessem empreender esse projeto, especialmente a concentração de renda, que era um problema estrutural no Brasil, e principalmente no Nordeste, na visão de Furtado. Destarte, era necessário que o Estado interviesse nesse processo e tentasse transformar tal estrutura: essa era uma solução para o combate ao subdesenvolvimento. "O desenvolvimento é a transformação do conjunto das estruturas de uma sociedade em função dos objetivos que se propõe alcançar essa sociedade" (FURTADO, 2003: 103).

Em suma, a existência da SUDENE é fruto da concepção de história de Furtado, não só pelas questões que envolvem as causas do subdesenvolvimento, mas principalmente pela crença nas instituições que poderiam combater os problemas estruturais, na convicção da possibilidade de mudança e transformação com o uso do conhecimento. No relatório do GTDN (1959), Furtado deixa claro que não poderia conceber uma política assistencialista, que buscava corrigir os problemas momentâneos, que continuavam se agravando com o tempo, e perpetuando a situação de atraso econômico do Nordeste. A proposta é uma ação nas raízes de problemas historicamente elaborados. Sendo assim, a SUDENE se torna uma solução para as correções dos problemas estruturais, historicamente construídos no Nordeste brasileiro, essa instituição foi a manifestação da teoria e prática intelectual de Furtado, motivada pela sua concepção de história em que o homem munido de conhecimento, atrelado a ação do Estado pode transformar seu contexto e acreditar na possibilidade de superação do subdesenvolvimento. 


\section{Fontes}

FURTADO, Celso (1950). Características gerais da economia brasileira. Revista Brasileira de Economia, v. 4, n. 1, p. 7-33.

FURTADO, Celso (1954). Economia brasileira: contribuição à análise de seu desenvolvimento. Rio de Janeiro: A Noite.

FURTADO, Celso (1956). Uma economia dependente. Rio de Janeiro: A Noite.

FURTADO, Celso (1958). Perspectivas da economia brasileira. Rio de Janeiro: ISEB.

FURTADO, Celso (1959a). Formação econômica do Brasil. Rio de Janeiro: Fundo da Cultura.

FURTADO, Celso (1959b). A operação Nordeste. Rio de Janeiro: Ministério da Educação e Cultura Instituto Superior de Estudos Brasileiros.

FURTADO, Celso (1961). Desenvolvimento e subdesenvolvimento. Rio de Janeiro: Fundo da Cultura.

FURTADO, Celso (1966). Subdesenvolvimento e estagnação na América Latina. Rio de Janeiro: Civilização Brasileira.

FURTADO, Celso (1985). A fantasia organizada. Rio de Janeiro: Paz e Terra.

FURTADO, Celso (1983). Teoria e Política do Desenvolvimento Econômico. São Paulo: Abril Cultural.

FURTADO, Celso (1989). A fantasia desfeita. São Paulo: Paz e Terra.

FURTADO, Celso (1997). Obra autobiográfica. Rio de Janeiro: Paz e Terra, v. 1.

FURTADO, Celso (2003). Raízes do subdesenvolvimento. Rio de Janeiro: Civilização Brasileira.

\section{Referências bibliográficas}

AGUIAR, Rosa Freire d'Aguiar (org) (2013). Essencial Celso Furtado. São Paulo: Penquin Classics Cia das Letras.

ARAÚJO, Tarcisio Patricio de; VIANNA, Salvador Teixeira Werneck; MACAMBIRA, Júnior. (Org.) (2009). 50 anos de formação econômica do Brasil. Rio de Janeiro: IPEA.

BIELSCHOWSKY, Ricardo (1995). Pensamento econômico brasileiro: o ciclo ideológico do desenvolvimentismo. 2. ed. Rio de Janeiro: Contraponto.

FONSECA, P. C. D (2008). A controvérsia entre metalismo e papelismo e a gênese do desenvolvimentismo no Brasil. In: Encontro da associação nacional dos centros de pós-graduação em Economia-- ANPEC, 36, Salvador, Bahia, 9-12 dez.

FONSECA, P.C.D; SALOMÃO, I (2017). O Sentido Histórico do Desenvolvimentismo brasileiro. Revista Economia Contemporânea, núm. Esp., p. 1-20.

GTDN (1959). Uma política de desenvolvimento Econômico para o Nordeste. Rio de Janeiro: Imprensa Nacional.

KOSELLECK, Reinhart (2006). Futuro passado: contribuição à semântica dos tempos históricos. Rio de Janeiro: Contraponto; Editora PUC-Rio.

LIMA, Marcos Costa; DAVID, Maurício Dias (Org.) (2008). A atualidade do pensamento de Celso Furtado. Goiânia: Verbena.

LIMA, Neilaine.R.R (2020). Conceitos, intelectuais e ideias: o entrelaçamento de diferentes dimensões do campo da História, no caso do debate entre Eugênio Gudin e Celso Furtado (1950-1964). História, debates e tendências, vol.20, n.1, p.70-87. 
LOVE, Joseph L (1998). A construção do Terceiro Mundo: teorias do subdesenvolvimento na Romênia e no Brasil. Tradução Patrícia Zimbres. Rio de Janeiro: Paz e Terra.

OLIVEIRA, Francisco de (2003). Política numa era de indeterminação: opacidade e reencantamento. In: SILVA, Fernando da et al. (Org.). República, liberalismo, cidadania. Piracicaba: Editora da Unimep.

ROSTOW, W.W (1974). Etapas do desenvolvimento econômico: um manifesto não comunista. São Paulo: Zahar.

SIRINELLI, J. (2003). Os intelectuais. In: RÉMOND, René (Org.). Por uma História Política. Rio de Janeiro: FGV.

SOUZA, D. D (et al) (2008). O Nordeste e a SUDENE. In: LIMA, Marcos Costa; DAVID, Maurício Dias (Org.). A atualidade do pensamento de Celso Furtado. Goiânia: Verbena.

Artigo recebido em 08 de fevereiro de 2020.

Aprovado em 23 de outubro de 2020.

DOI: $10.12957 /$ intellectus.2020.53942 